\title{
General Psychiatry Challenges and opportunities in mental health services during the COVID-19 pandemic
}

Daihui Peng (D) , Zhen Wang (D) , Yifeng Xu

To cite: Peng D, Wang Z, $X u Y$. Challenges and opportunities in mental health services during the COVID-19 pandemic. General Psychiatry 2020;33:e100275. doi:10.1136/ gpsych-2020-100275

Received 19 May 2020 Revised 29 July 2020 Accepted 31 July 2020
Check for updates

(C) Author(s) (or their employer(s)) 2020. Re-use permitted under CC BY-NC. No commercial re-use. See rights and permissions. Published by BMJ.

Shanghai Mental Health Center, Shanghai Jiao Tong University School of Medicine, Shanghai, China

Correspondence to Dr Zhen Wang; wangzhen@smhc.org.cn

Dr Yifeng Xu; xuyifeng@shmc.org.cn
As of 12 March 2020, the WHO upgraded the status of COVID-19 from epidemic to pandemic. ${ }^{1}$ Globally, as of 20 July 2020, 14707 451 confirmed cases of COVID-19, including 609985 deaths, have been reported by an interactive web-based dashboard released by Johns Hopkins University. ${ }^{2}$ Strict provisions and strategies have been implemented to suppress or mitigate the spread of the COVID-19 pandemic, such as governmentimposed contact tracing and quarantine, lockdown, social and physical distance measures, and closure of non-essential facilities and services. The global spread of the COVID-19 pandemic and rapid escalation response undoubtedly put enormous stress on patients with confirmed or suspected COVID-19, medical personnel and even the public, increasing the risk of mental health problems.

\section{CHALLENGES FOR MENTAL HEALTH SERVICE DURING THE COVID-19 PANDEMIC}

This unprecedented crisis poses great challenges for mental health services. First, high contagion, inherent scientific uncertainties and imposition of strict quarantine inevitably increase patients' fear and stigma, which in turn create barriers to seeking support for appropriate medical treatment and a psychological crisis intervention. One report addressed a similar issue about stigma and discrimination during the severe acute respiratory syndrome outbreak. ${ }^{3}$ Additionally, although most people experiencing public health emergency do not succumb to negative psychosocial outcomes, some individuals are more sensitive to emotional distress owing to individuals' biological vulnerability, psychosocial factors and coping strategies. ${ }^{4}$ A nationallevel and large-scale survey, involving 52739 participants in China, assessed the magnitude of psychological burden in the general population during the COVID-19 crisis and found that almost $35 \%$ of responders experienced psychological distress. ${ }^{5}$ Psychosocial support and psychoeducation should be implemented to protect the public's mental health. As for the front-line responders themselves (including medical staff, police, social workers, volunteers and management personnel), no specific treatment for the life-threatening viral infection, shortage of medical equipment, fear of contagion and of infecting loved ones, and overwhelming workload are among the major contributors to psychological problems. In the midst of this crisis, one survey reported that a considerable proportion of front-line medical personnel in China suffered from depression symptoms $(50.4 \%)$, anxiety ( $44.6 \%)$, insomnia $(34.0 \%)$ and distress $(71.5 \%) .{ }^{6}$ Finally, some marginalised populations (such as the elderly, people with chronic physical illnesses, individuals residing in congregate settings and those with pre-existing psychological conditions) have largely been overlooked as much attention has been paid to infected patients, their family members, the bereaved and front-line medical personnel exposed to COVID-19. In particular, people with pre-existing psychological conditions are susceptible to adverse psychosocial outcomes (eg, anxiety, depression, insomnia, irritability and contaminationrelated behavioural tendencies) in the COVID-19 crisis. In light of stringent travel restrictions, strong fears of contamination and an overburdened health system, they hardly have access to maintain treatments and regular follow-up visits, yielding pre-existing symptom worsening or relapse.

\section{MENTAL HEALTHCARE PREPAREDNESS AND RESPONSE IN CHINA}

To efficiently mitigate the mental health consequences triggered by the COVID-19 pandemic, the National Health Commission of the People's Republic of China and the 


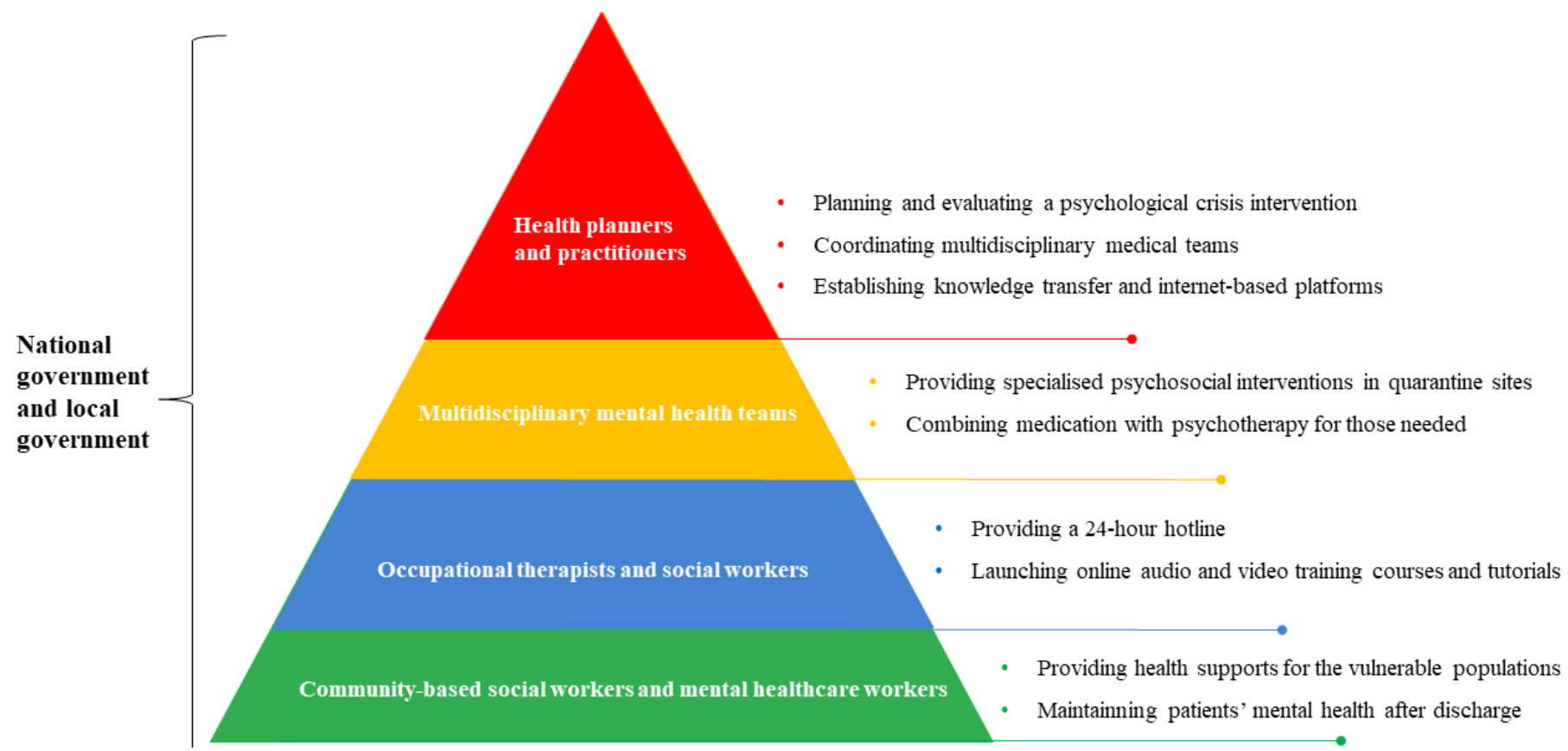

Figure 1 The progress of mental health services during the outbreak in China. Adapted from the Guiding Principles of Emergency Psychological Crisis Intervention for the COVID-19 pandemic launched by the National Health Commission of the People's Republic of China. ${ }^{78}$

Joint Prevention and Control Office of the State Council have released comprehensive and systematic emergency psychological crisis interventions with the engagement of the whole society (including health planners and health authorities, multidisciplinary mental health teams, community-based social groups and the public) (figure 1). ${ }^{78}$ First, this prompt and well-orchestrated emergency response addressed mental health issues at the organisational level through planning and evaluating evidence-based interventions, specific intervention strategies for target populations and the involvement of social services. Specifically, health planners and practitioners incorporate theoretical and empirical evidence into planning and evaluating psychological crisis interventions. Multidisciplinary mental health teams (including psychiatrists, psychologists, psychiatric nurses, occupational therapists and social workers) have been established to eliminate psychological barriers and provide specialised psychosocial interventions in quarantine sites. Occupational therapists and social workers have provided psychological support and psychoeducation to infected patients, especially to those living in high-prevalence areas. Those with serious mental health problems need referrals for psychiatrists, and sometimes a combination of psychotherapy and medication is needed. Meanwhile, community-based social workers and mental healthcare workers are not only dedicated to providing resources and health supports for the vulnerable populations but they also play an important role in maintaining patients' mental health after discharge. As for front-line responders themselves, specialised infection prevention and control training, enough supply of personal protective equipment, and the establishment of psychosocial support for their families should be encouraged to address their concerns and stress. Experiencing the COVID-19 crisis, the public strives to create a good social atmosphere for those with mental health problems and to eliminate the stigma surrounding mental health issues. The COVID-19 pandemic has both alarming implications and opportunities for integrating mental health services into the public health response system and ultimately improving mental health crisis response services.

Second, due to human-to-human transmission of COVID-19, the ever-increasing internet and social media (eg, WeChat, TikTok and Zoom) have been harnessed to perform online psychological crisis interventions. National and provincial psychology organisations have rapidly launched online self-help books to raise public awareness of emotional prevention and established knowledge transfer and internet-based platforms to provide online counselling and intervention for vulnerable populations. For instance, psychologists and psychiatrists in Shanghai Mental Health Center have launched audio and video training courses and tutorials for the general population and stretched medical staff to combat mental health conditions (eg, insomnia, fear and anxiety). ${ }^{9}$ In addition, the widespread availability of digital services undoubtedly facilitates spontaneous and efficient communication and cooperation among health providers. Given that most workers in healthcare settings have no or little experience in dealing with mental health problems, implementation of internet-delivered psychological counselling and guidance enables health providers to quickly identify patients' psychosocial health needs. During the public mental health crisis, internet-based screening and psychological intervention are reshaping traditional mental healthcare 
patterns, providing new insights into the development of online mental health services.

\section{OPPORTUNITIES AND SUGGESTIONS}

During this crisis, opportunities to improve mental health services must be seized by integrating psychological crisis interventions into COVID-19 healthcare preparedness and response. Undoubtedly, the COVID-19 crisis is a double-edged sword for mental health services. In case of a similar public health crisis in the future, government and local authorities should formulate a multi-tiered response to intervention and integrate this structured psychological intervention into public health emergency preparedness and response. With the ever-emerging online mental health services, specialised psychiatric hospitals and general hospitals should enhance multidisciplinary collaborations and jointly carry out remote consultations to improve the quality of emergency psychological crisis interventions.

Contributors DP wrote the draft and made revisions. ZW and YX reviewed the article and made revisions.

Funding The authors have not declared a specific grant for this research from any funding agency in the public, commercial or not-for-profit sectors.

Competing interests None declared.

Patient consent for publication Not required.

Provenance and peer review Not commissioned; externally peer reviewed.

Open access This is an open access article distributed in accordance with the Creative Commons Attribution Non Commercial (CC BY-NC 4.0) license, which permits others to distribute, remix, adapt, build upon this work non-commercially, and license their derivative works on different terms, provided the original work is properly cited, appropriate credit is given, any changes made indicated, and the use is non-commercial. See: http://creativecommons.org/licenses/by-nc/4.0/.

ORCID iDs

Daihui Peng http://orcid.org/0000-0003-4338-967X

Zhen Wang http://orcid.org/0000-0003-4319-5314

Yifeng Xu http://orcid.org/0000-0002-0403-1141

\section{REFERENCES}

1 World Health Organization. Who announces COVID-19 outbreak a pandemic, 2020. Available: http://www.euro.who.int/en/health-topics/ health-emergencies/coronavirus-covid-19/news/news/2020/3/whoannounces-covid-19-outbreak-a-pandemic [Accessed 12 Mar 2020].

2 Dong E, Du H, Gardner L. An interactive web-based dashboard to track COVID-19 in real time. Lancet Infect Dis 2020;20:533-4.

3 Person B, Sy F, Holton K, et al. Fear and stigma: the epidemic within the SARS outbreak. Emerg Infect Dis 2004;10:358-63.

4 Schneiderman N, Ironson G, Siegel SD. Stress and health: psychological, behavioral, and biological determinants. Annu Rev Clin Psychol 2005;1:607-28.

5 Qiu J, Shen B, Zhao M, et al. A nationwide survey of psychological distress among Chinese people in the COVID-19 epidemic: implications and policy recommendations. Gen Psychiatr 2020;33:e100213.

6 Lai J, Ma S, Wang Y, et al. Factors associated with mental health outcomes among health care workers exposed to coronavirus disease 2019. JAMA Netw Open 2020;3:e203976.

7 National Health Commission of the People's Republic of China Work plan of psychological assistance and medical social work amid COVID-19 outbreak, 2020. Available: http://en.nhc.gov.cn/2020-03/13/ c 77687.htm [Accessed 13 Mar 2020]

8 Joint Prevention and Control Office of the State Council. Psychological counseling and social work service plan for patients with COVID-19, isolated people and their family members, 2020. Available: http:// www.nhc.gov.cn/jkj/s5888/202004/32701ef2e5c940cb8e0e416d babb4a4d.shtml [Accessed 7 Apr 2020].

9 Shanghai Mental Health Center, Shanghai Municipal Center of Mental Disease Prevention and Control, Shanghai Mental Health Association. Psychological crisis intervention during the novel coronavirus outbreak: being your guardian angel, 2020. Available: http://m.ajmide. $\mathrm{com} / \mathrm{m} / \mathrm{brand}$ ? id=10722564 [Accessed 30 Jan 2020]

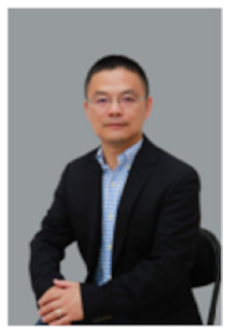

Dr. Daihui Peng obtained a bachelor's degree in psychiatry from Hubei Medical University in Hubei, China, in 1994; a master's degree in psychiatry from Wuhan University in Hubei, China, in 2002; and a doctorate of psychiatry from Fudan University in Shanghai, China, in 2006. He is now working as the Director of the Division of Mood Disorders, Shanghai Mental Health Center, Shanghai Jiao Tong University School of Medicine in Shanghai, China. His research interests focus on the neurobiology and neuroimmune mechanisms of major depressive disorder and bipolar disorder. Moreover, he has conducted several epidemiological and clinical intervention studies on mood disorders. As a chief psychiatrist, he also specializes in the treatment of refractory depression and several severe psychiatric disorders. 